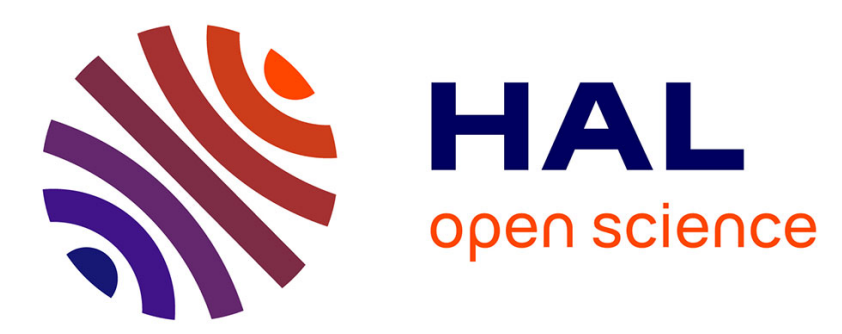

\title{
LES of knocking in engines using dual heat transfer and two-step reduced schemes
}

\author{
Antony Misdariis, Olivier Vermorel, Thierry Poinsot
}

\section{To cite this version:}

Antony Misdariis, Olivier Vermorel, Thierry Poinsot. LES of knocking in engines using dual heat transfer and two-step reduced schemes. Combustion and Flame, 2015, vol. 162 ( $\left.\mathrm{n}^{\circ} 11\right)$, pp. 43044312. 10.1016/j.combustflame.2015.07.023 . hal-01235064

\section{HAL Id: hal-01235064 \\ https://hal.science/hal-01235064}

Submitted on 27 Nov 2015

HAL is a multi-disciplinary open access archive for the deposit and dissemination of scientific research documents, whether they are published or not. The documents may come from teaching and research institutions in France or abroad, or from public or private research centers.
L'archive ouverte pluridisciplinaire HAL, est destinée au dépôt et à la diffusion de documents scientifiques de niveau recherche, publiés ou non, émanant des établissements d'enseignement et de recherche français ou étrangers, des laboratoires publics ou privés. 


\section{Open Archive TOULOUSE Archive Ouverte (OATAO)}

OATAO is an open access repository that collects the work of Toulouse researchers and makes it freely available over the web where possible.

This is an author-deposited version published in : http://oatao.univ-toulouse.fr/ Eprints ID : 14489

To link to this article : DOI:10.1016/j.combustflame.2015.07.023 URL : http://dx.doi.org/10.1016/j.combustflame.2015.07.023

To cite this version : Misdariis, Antony and Vermorel, Olivier and Poinsot, Thierry LES of knocking in engines using dual heat transfer and two-step reduced schemes. (2015) Combustion and Flame, vol. $162\left(\mathrm{n}^{\circ} 11\right)$. pp. 4304-4312. ISSN 00102180

Any correspondance concerning this service should be sent to the repository administrator: staff-oatao@,listes-diff.inp-toulouse.fr 


\title{
LES of knocking in engines using dual heat transfer and two-step reduced schemes
}

\author{
Antony Misdariis ${ }^{\mathrm{a}, \mathrm{b}, *}$, Olivier Vermorel ${ }^{\mathrm{b}}$, Thierry Poinsot ${ }^{\mathrm{c}}$ \\ a Renault SAS, 1 Allée Cornuel, 91570 Lardy, France \\ ${ }^{\mathrm{b}}$ CERFACS, CFD Team, 42 Avenue G. Coriolis, 31057 Toulouse Cedex 01, France \\ ' Institut de Mécanique des Fluides de Toulouse, CNRS, Avenue C. Soula, 31400 Toulouse, France
}

Keywords:

LES

Knock

Autoignition

Internal combustion engine

Heat transfert

\begin{abstract}
A B S T R A C T
Large Eddy Simulation of knocking in piston engines requires high-fidelity physical models and numerical techniques. The need to capture temperature fields with high precision to predict autoignition is an additional critical constraint compared to existing LES in engines. The present work presents advances for LES of knocking in two fields: (1) a Conjugate Heat Transfer (CHT) technique is implemented to compute the flow within the engine over successive cycles with LES together with the temperature field within the cylinder head walls and the valves and (2) a reduced two-step scheme is used to predict both propagating premixed flames as well as autoignition times over a wide range of equivalence ratios, pressures and temperatures. The paper focuses on CHT which is critical for knocking because the gas temperature field is controlled by the wall temperature field and knocking is sensitive to small temperature changes. The CHT LES is compared to classical LES where the temperatures of the head and the valves are supposed to be homogeneous and imposed empirically. Results show that the skin temperature field (which is a result of the CHT LES while it is a user input for classical LES) is complex and controls knocking events. While the results of the CHT LES are obviously better because they suppress a large part of the empirical specification of the wall temperatures, this study also reveals a difficult and crucial element of the CHT approach: the description of exhaust valves cooling which are in contact with the engine head for part of the cycle and not in the rest of the cycle, leading to difficulties for heat transfer descriptions between valves and head. The CHT method is successfully applied to an engine studied at IFP Energies Nouvelles where knocking characteristics have been studied over a wide range of conditions.
\end{abstract}

\section{Introduction}

To increase the efficiency of reciprocating engines, downsizing has become a new standard in the automotive industry [1]. By combining smaller cylinder sizes with turbo-chargers, engines can be operated in a region of higher efficiency. For moderate downsizing levels, this technique enables to decrease fuel consumption significantly and thus pollutants emissions. However abnormal combustions prevent engine manufacturers from using advanced levels of downsizing. Abnormal combustion results from the competition between the turbulent propagation of the premixed flame initiated by the spark plug and the spontaneous ignition of the fresh gas. When high pressure and high temperature are encountered in the fresh gas in front of the flame front (also called end-gas), the auto-ignition delay drops

* Corresponding author at: CERFACS, CFD Team, 42 Avenue G. Coriolis, 31057 Toulouse Cedex 01, France.

E-mail address: antony.misdariis@cerfacs.fr (A. Misdariis). and can become lower than the time needed by the premixed flame to burn the charge. This kind of auto-ignition events leads to abnormal combustions such as knocking or rumble and can destroy the engine. Over the last decades, the increase of engines compression ratios lead to the same issues [2,3] and a better understanding of heat transfer and engine cooling allowed to control knocking. Nowadays, such fluid/solid interactions remain a key-parameter but it is not sufficient to control abnormal combustions in highly downsized engines. Increasing the engine resistance to knocking requires a better understanding of these phenomena. Although optical diagnostics are not easy to perform, existing experimental studies [4-6] highlighted some key features leading to abnormal combustions: (1) the intensity of knock is linked to the portion of fresh gas when auto-ignition occurs [7] and (2) detonation waves may appear in knocking cycles. The basic mechanism leading to detonation in such flows was studied by Zeldovich [8] who showed that a 1D temperature gradient in a flow close to auto-ignition could initiate a detonation wave. This mechanism was studied later by Bradley et al. [9] or Clavin et al. [10] and 
Table 1

Properties of the materials used in the CHT simulation.

\begin{tabular}{llrr}
\hline & Symbol & Cast iron & steel \\
\hline Density $\left[\mathrm{kgm}^{-3}\right]$ & $\rho$ & 2675 & 7500 \\
Heat capacity $[\mathrm{J} /(\mathrm{kg} \mathrm{K})]$ & $C p$ & 900 & 450 \\
Heat conductivity $[\mathrm{W} /(\mathrm{m} \mathrm{K})]$ & $\lambda$ & 100 & 36 \\
\hline
\end{tabular}

has become the prototype configuration used to illustrate how detonation can begin in an engine. Even though detonation can hardly be observed directly inside a piston engine several studies were carriedout in canonical configurations $[8,11]$ suggesting that conditions were indeed favorable to detonation in knocking engines.

In this context, Large Eddy Simulations (LES) can provide detailed information to analyze abnormal combustion. Peters et al. [12] used simulations to identify regions where a Deflagration to Detonation Transition (DDT) can occur based on cold flow LES results and on the Zeldovich et al. theory. Robert et al. [13] proved that LES can be used to evaluate the knocking tendency of an experimental engine. They retrieved quantitatively the experimental behavior of the real engine and performed a first analysis of abnormal combustion thanks to LES.

Obviously temperature plays a major role for knock and in a real engine the temperature field is expected to control knocking events to a large extent. For instance, wall heat transfer dictates the temperature level at Top Dead Center (TDC) when ignition is performed just before knock can begin near hot regions. This issue becomes even more important for engines running with abnormal combustion where local and intermittent hot spots found near high temperature walls can initiate auto-ignition inside fresh gases. In that sense, the use of realistic wall temperatures is of first importance when studying abnormal combustions with numerical simulations. The potential benefits of conjugate heat transfer simulations for piston engines flows are pointed out in [14] and the same methodology is used in [15]. These studies proved that abnormal combustion events are influenced by wall temperatures and that Conjugate Heat Transfer (CHT) must be accounted for in these simulations, even in the context of RANS simulations. Here, the impact of CHT on knocking is investigated using individual cycles computed with LES. The drawback of this method is that hundreds of cycles would be needed to account for cycle to cycle variabilities and obtain converged statistics, thus implying large CPU cost and simulation times. In this context, recent LES work [16-18] proved that, with a limited number of cycles, LES can predict cyclic variations. More recently, it was also shown that LES can provide detailed informations on knocking with a few engine cycles only [13]. The scope of the present paper is to improve abnormal combustion LES by including a comprehensive description of conjugate heat transfer with LES.

\section{Configuration and methodology}

In an engine, conjugate heat transfer controls wall temperatures and has a strong impact on combustion [19] because of the long residence time of the fresh gas in the cylinder prior to combustion triggered around TDC. The large variations of the combustion chamber volume and thus of the thermodynamic conditions promote heat exchanges at the boundaries and impact the combustion process. The wall temperatures used in numerical simulations are usually obtained from experimental measurements or from a priori estimations. This approach can provide an appropriate global behavior but local information is missing. In particular, the sophisticated cooling system used for the cylinder head can lead to temperature in-homogeneities that can have an impact on abnormal combustion. Only one hot wall zone can be enough to trigger knocking. This situation differs from 'classical' LES in engines, far from knocking conditions where wall temperatures play a more limited role [20-22]. In this paper,

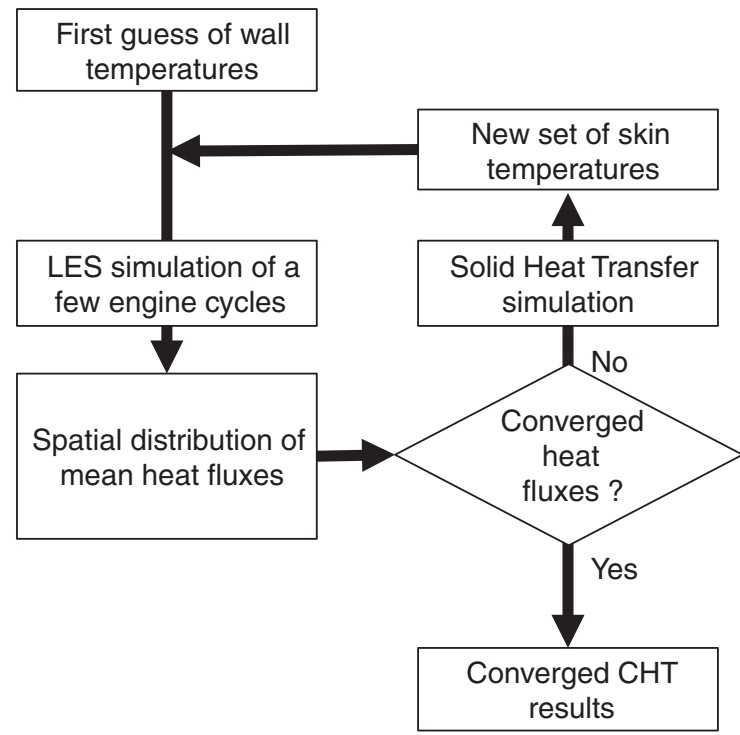

Fig. 1. Diagram of the weak coupling algorithm to perform a CHT simulation.

conjugate heat transfer is solved by means of a fully coupled simulation between fluid and solid so that relevant boundary conditions can be used to study knocking. While such studies have already been performed using RANS [15], they require much more care in a true LES framework as described in the next section.

\subsection{Coupling methodology}

In order to use realistic boundary conditions, a common strategy consists in using two different solvers: one for LES and another one to solve the heat equation in the solid domain. In such simulations, the characteristic time of the heat conduction in the solid $\tau_{s} \sim L^{2} / D_{S}$ (with $L$ the solid characteristic length and $D_{s}$ the solid diffusivity) is often several orders of magnitude higher than the combustion characteristic time $\tau_{c} \sim \delta_{I} / S_{L}$ (with $\delta_{I}$ the flame thickness and $S_{L}$ the flame speed). For instance, assuming a valve head of $L=10 \mathrm{~mm}$ and with the properties of steel (Table 1), the conduction characteristic time is:

$\tau_{s}=\frac{L^{2}}{\lambda /(\rho C p)}=\frac{0.01^{2}}{36 /(7500.450)}=9 \mathrm{~s}$

while for an iso-octane/air flame at 40 bar and $700 \mathrm{~K}$, the combustion characteristic time is:

$\tau_{c}=\delta_{l} / S_{L}=\frac{1.10^{-4}}{1.0}=1.10^{-4} \mathrm{~s}$

For this particular case, the conduction characteristic time is five orders of magnitude bigger than the conduction characteristic time: the solid acts like a low-pass filter and only sees a mean heat flux coming from the fluid domain. A numerical difficulty directly introduced by this time scales difference is that the convergence speeds differs in the fluid and in the solid domains. The convergence for the solid temperature is too long to be computed with LES. In practice however, this time scales difference can be exploited efficiently by recognizing that only a weak coupling between the two domains is sufficient. Decoupling the computations of LES in the cylinder and temperature in the solid walls allows to reach a converged state at the fluid/solid interface by only considering a mean averaged field of heat fluxes as inputs for the heat transfer simulation in the solid. The methodology used to obtain the converged conjugated heat transfer at the fluid/solid interface is based on such a weak coupling (Fig. 1). The two solvers are run sequentially: first, an initial set of wall skin temperatures is obtained from experimental measurements or from 0D 


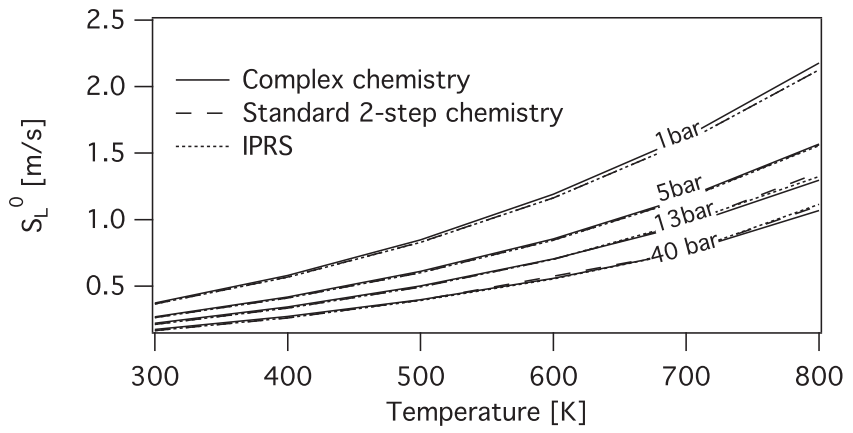

Fig. 2. Comparison of 1D stoichiometric isooctane/air laminar flame speed with complex chemistry [36], the standard two-step chemistry and the IPRS model.

simulations [23]. This set of wall temperature is used to compute the fluid dynamics thanks to the LES solver and wall Heat Fluxes (HF) are locally integrated over the full engine cycle. Then, the Heat Transfer (HT) solver is used to compute the steady temperature field inside the solid domain. Finally, the converged temperature at the fluid/solid interface is used to update the wall temperature field of the LES simulation. This coupling loop is performed until convergence of the heat fluxes and temperature at the interface.

\subsection{Numerical set-up}

In the present work, the fully compressible explicit code (called AVBP) is used to solve the filtered multi-species 3D Navier-Stokes equations with realistic thermochemistry on unstructured meshes [24,25]. Based on the $\mathrm{ESO}_{2}$ approach [26], numerics is handled with the second-order accurate in space and time Lax-Wendroff scheme [27] and a Two-step Taylor-Galerkin finite element scheme (TTG), third-order accurate in space and time [28] for phases which require increased accuracy (compression and combustion). The Smagorinsky sub-grid scale model is used [29] and boundary conditions use the NSCBC approach [30]. A simple 2-step scheme chemistry is used and sub-grid scale combustion is accounted for with the Thickened Flame for LES (TFLES) model since it has been successfully tested in numerous configurations outside piston engines [31-34] as well as in piston engines [16,17]. Auto-ignition delays predictions is ensured by the Ignition to Propagation Reduced Scheme (IPRS) model [35]. The main idea of this model is that the pre-exponential constant $A$ of the first reaction (fuel oxidation) takes different values at low and high temperatures. The low-temperature value of $A$ controls the autoignition time while the high-temperature value controls the flame speed. With this formalism, the low-temperature constant $A_{A I}$ is replaced by a function of the fresh gas conditions, adjusted to predict the autoignition delay over a wide range of pressures and temperatures while the high-temperature value $A_{\text {prop }}$ ensures the right flame speeds over the same temperature and pressure range as shown in [35]. Note that this model predict the auto-ignition delay only and is not able to reproduce the cold flame phenomena. Figures 2 and 3 show the results obtained with IPRS in 1D laminar flames and homogeneous reactors for operating conditions corresponding to the ones observed in the engine studied in the present paper. The Energy Deposition (ED) model [37] is used for spark ignition and moving meshes are handled with the ALE formalism [38]. Because of the high values of the Reynolds numbers, resolution of thermal and aerodynamic boundary layers would require very refined meshes at walls and would lead to unaffordable CPU cost when dealing with complex configurations. This issue is even more critical in IC engine simulations when using moving meshes: the mesh displacement would introduce a large deformation of the smallest mesh elements that would lead to numerical errors. Here wall functions were used $[21,32,39,40]$.

The energy equation inside the solid domain is solved by the AVTP solver [41]. Spatial discretization is handled with a second-order

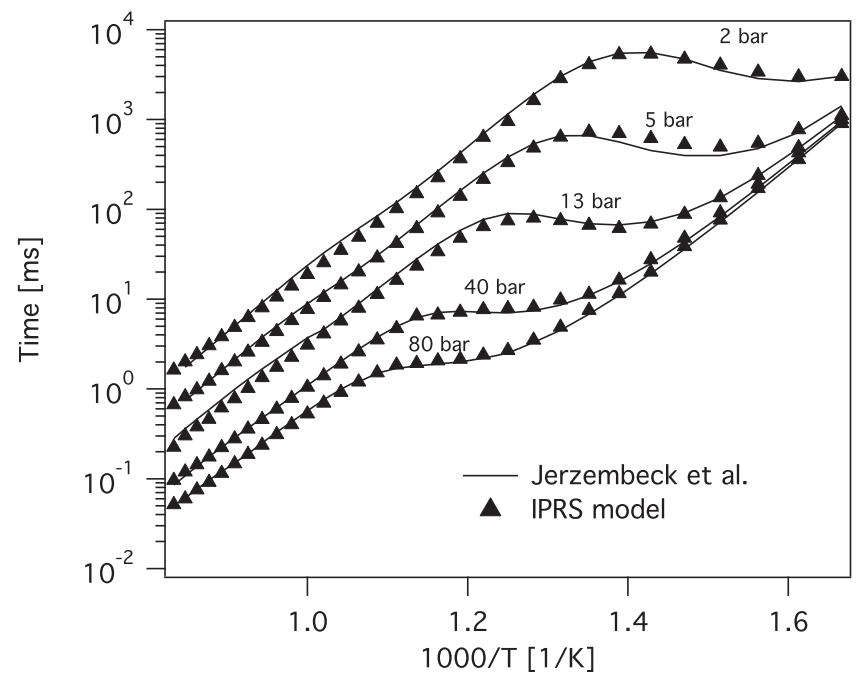

Fig. 3. Comparison of AI delays obtained with a 2-step chemistry and a reference chemistry [36] in an homogeneous reactor.

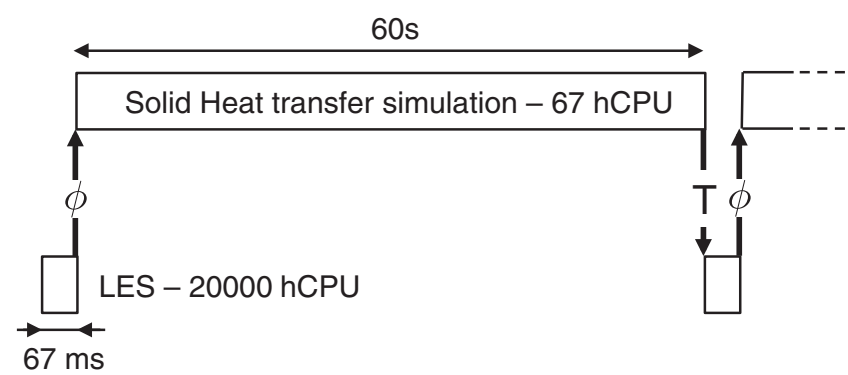

\section{CHT iteration 1}

Fig. 4. Schematic of the Conjugated Heat Transfer (CHT) simulation.

Galerkin scheme [42] and temporal integration uses a first-order forward implicit scheme. The resolution of the implicit system is done with a parallel matrix free conjugate gradient method [43]. Heat fluxes are determined by means of a Fourier's law and temperature dependent heat conductivity coefficients and heat capacities are used.

As shown in Fig. 4, the LES simulation for one cycle represents $67 \mathrm{~ms}$ of physical time (for an engine speed of $1800 \mathrm{rpm}$ ) while $60 \mathrm{~s}$ of physical time is needed to reach steady state inside the solid. However, thanks to the use of an implicit time marching, the heat transfer simulation inside the solid uses large time-steps and the final cost is negligible compared to the LES simulation. Eventually, the cost of the CHT simulation is only due to the extra LES simulations performed at each $\mathrm{CHT}$ iteration to reach a converged temperature field at the fluid/solid interface.

\subsection{Experimental configuration and operating point}

The target configuration is an experimental mono-cylinder 4 valves turbo-charged ECOSURAL engine shown in Fig. 5. This engine is installed at IFP Energies Nouvelles in the framework of the french ANR (Research National Agency) ICAMDAC project to study abnormal combustion in downsized spark-ignited engines. The spatial discretization uses full tetrahedral meshes for the fluid and solid domains. The fluid domain begins in the inlet plenum and finishes on the outlet plenum, a procedure which has been shown to provide the required accuracy for LES by specifying boundary conditions far away from the cylinder $[17,21]$. The mesh size for the fluid domain 


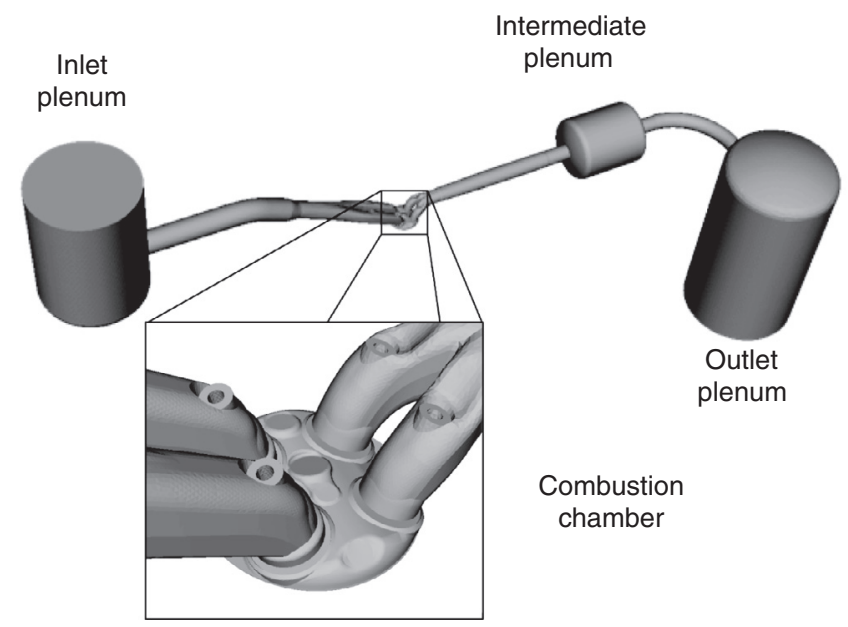

Fig. 5. Sketch of the experimental Ecosural engine test bench.

Table 2

Main engine specifications. Crank Angle Degrees (CAD) are relative to combustion top dead center. IVO and IVC respectively stand for Inlet Valve Opening and Closure while EVO and EVC stand for Exhaust Valve Opening and Closure.

\begin{tabular}{ll}
\hline Compression ratio [-] & 10.64 \\
Bore [mm] & 77.0 \\
Stroke [mm] & 85.8 \\
Connecting rod length [mm] & 132.2 \\
IVO/IVC [CAD] & $353 /-162$ \\
EVO/EVC [CAD] & $142.5 /-352.5$ \\
\hline
\end{tabular}

varies between 2.2 and 12 million cells while a fixed 1.7 million cells mesh is used for the solid domain. As shown in Fig. 6, the mesh at the fluid/solid interface is the same between the two domains. Two metals are accounted for in the CHT solver: the cylinder head is made of cast iron while steel is used for valves. The properties of cast iron and steel are summarized in Table 1.

The engine geometrical specifications (Table 2) and the operating point described in Table 3 correspond to the knocking conditions. For this regime, the dynamics of the flow predicted by LES were validated against PIV measurements [44].

\section{Conjugate heat transfer simulation}

All LES of piston engines require the specification of the wall temperatures. In the present work, two methods were used to obtain these quantities:

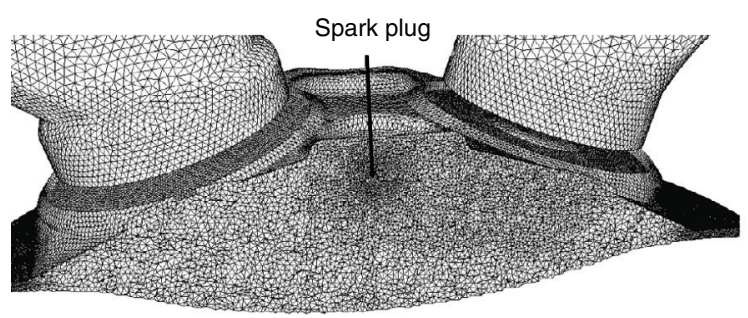

Table 3

Definition of the operating point chosed in the ICAMDAC database to study the knocking phenomena. IMEP stands for Indicated Mean Effective Pressure.

\begin{tabular}{ll}
\hline Engine rotation speed [rpm] & 1800 \\
IMEP [bar] & 19.0 \\
Intake pressure [bar] & 1.8 \\
Intake temperature [K] & 308 \\
Fuel [-] & $C_{8} H_{18}$ \\
\hline
\end{tabular}

Table 4

Skin wall temperatures obtained from OD simulations used for the empirical simulation [13].

\begin{tabular}{ll}
\hline Patch & Temperature $[\mathrm{K}]$ \\
\hline Cylinder head & 409 \\
Intake valves & 639 \\
Exhaust valves & 784 \\
\hline
\end{tabular}

- The usual method is to assume that (1) the chamber walls can be decomposed in isothermal elements: piston head, intake, exhaust valves and (2) the temperature of these elements is known, usually obtained either through a global energy balance or through empiric evaluations (this method is called empirical here).

- The CHT method where heat transfer in the walls (cylinder head and valves) is coupled to LES to obtain the skin wall temperature by a fully coupled simulation (called CHT here).

Note that in the empirical approach, the elements temperatures are often tuned to match experimental observations (volumetric efficiency, heat losses, etc.). Here we use the wall temperatures proposed for the same engine by Robert et al. [13] (Table 4). For the CHT approach, walls temperatures are a result of the computation and not an input data.

During one cycle the diffusion through the cylinder head and valves is actually not steady because of moving parts, of the unsteadiness of fluid dynamics and of the intermittency of combustion. For instance, for an engine cycle of $720 \mathrm{CA}$, the heat flux to the exhaust valve is high during combustion and exhaust phases while it is low during the intake stroke because of the low temperature of the fresh gases. In practice, however, because of the difference in characteristic times between heat diffusion inside the solid and flow motion in the cylinder, the solid acts as a low-pass filter and receives a heat flux coming from the fluid domain which can be averaged over the whole engine cycle, allowing to decouple LES and heat transfer codes. The most significant complexity for the CHT method is the description of the diffusive heat fluxes between valves and cylinder head. When valves are closed, heat can diffuse from the valve to the cylinder head depending

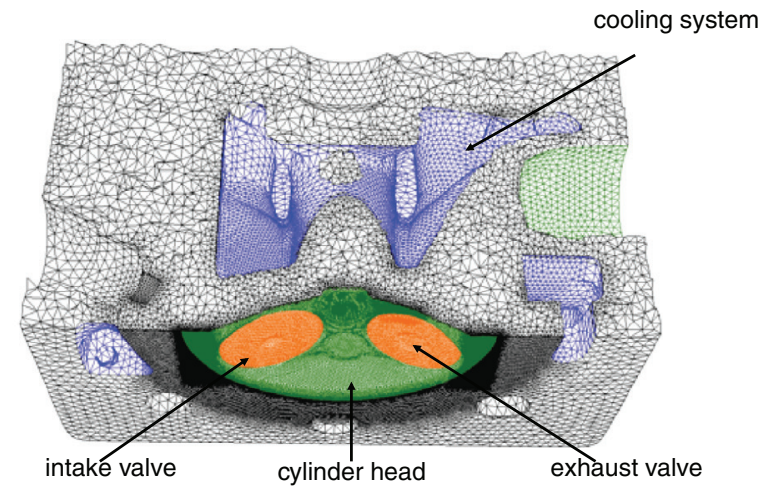

Fig. 6. Illustration of a typical mesh for the LES simulation (left) and for the CHT simulation (right). 


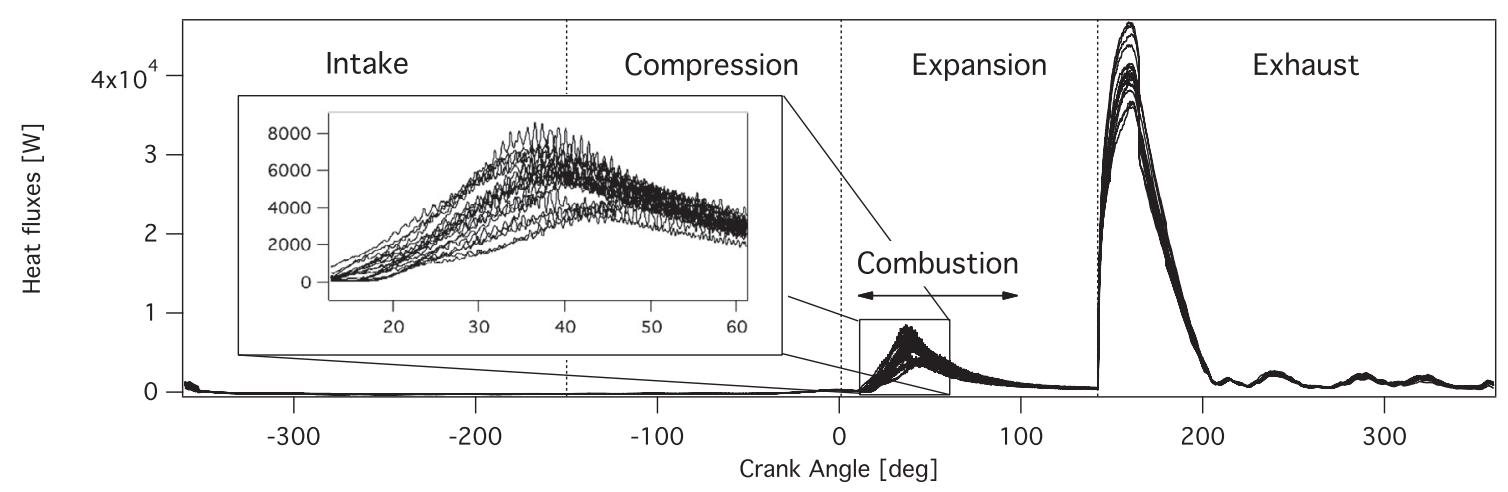

Fig. 7. Heat fluxes through the cylinder head during 15 consecutive cycles.

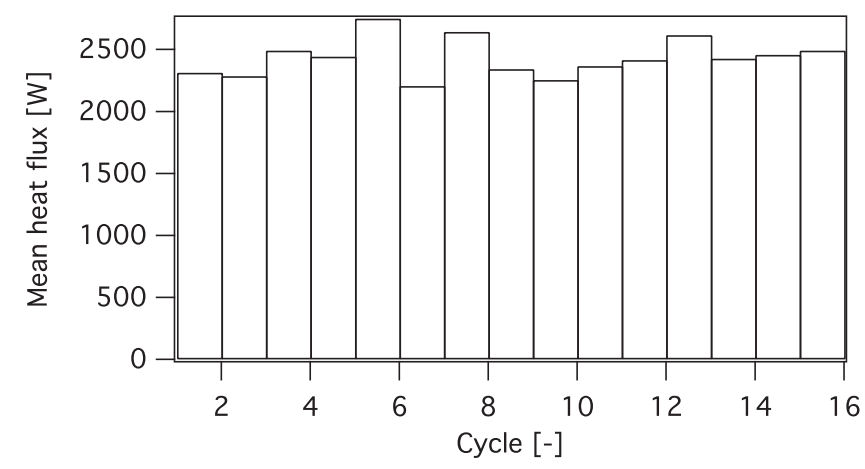

Fig. 8. Mean heat flux between the cylinder head and the fluid integrated over each engine cycle.

on the heat resistance of the contact zones between valves and cylinder head which is controlled by the force of the valve spring [45]. On the other hand in the open position, no thermal exchange can occur between the valve seat and the cylinder head. This geometry change has proved to be a major difficulty for the CHT approach because it controls the exhaust valve temperature and therefore the onset of knocking. The first part of this paper (Section 3.1) assumes that during the whole engine cycle, valves remain in the closed position as far as heat fluxes in the engine walls in concerned. This assumption clearly over-estimates the exhaust valve cooling and leads to lower temperatures. This problem is addressed in Section 3.4.

\subsection{Heat transfer cycle-to-cycle variability}

In spark ignited piston engines RMS pressures due to cycle-tocycle variability can reach several percents of the mean in-cylinder pressure. Cycle to cycle variability can also affect heat fluxes through the walls. In order to evaluate the variability of heat fluxes, Fig. 7 shows the value of the total flux to the cylinder head (valves are not included) obtained from LES for 15 consecutive engine cycles with the empirical approach and reveals a significant variability. For engine cycles where the whole mixture is burned quickly, pressure and temperature in the cylinder are high and increase thermal exchanges at the boundaries leading to large and variable fluxes during the combustion phase. However, Fig. 7 also shows that the main flux from the fluid to the cylinder head occurs during the exhaust stroke when the cylinder is filled with hot gases and high velocities caused by the exhaust valve opening. For this engine, all the fuel is consumed when the exhaust valves open, so that the temperature inside the cylinder is almost the same for all cycles. Even though the instantaneous flux to the cylinder head varies from cycle to cycle (Fig. 7), its value averaged over each cycle exhibits much less variation (Fig. 8). To evaluate the impact of these variations on combustion, the engine cycle

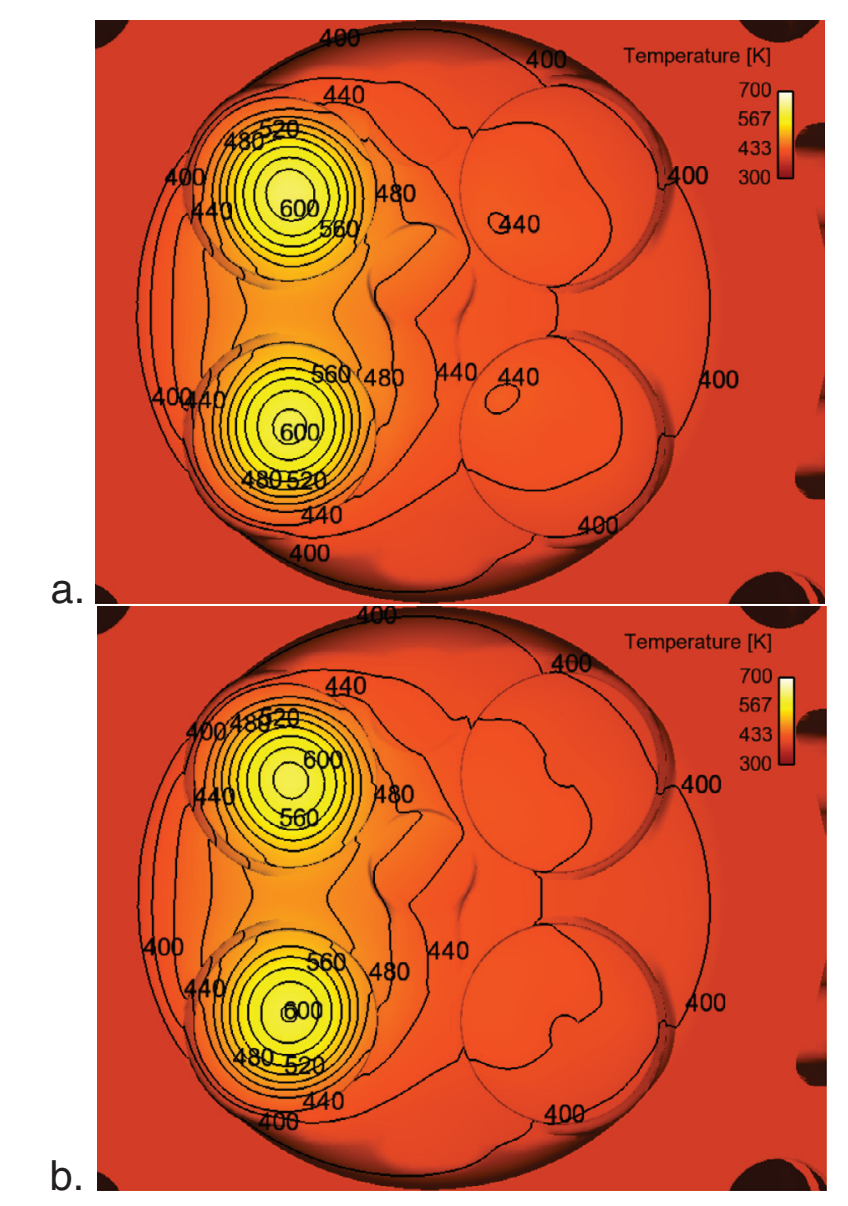

Fig. 9. Converged temperature on the solid skin after the first CHT iteration. (a) Engine cycle with the highest mean heat transfer and (b) engine cycle with the lowest heat transfer.

showing the highest heat fluxes and the engine cycle with the lowest heat fluxes were used as boundary conditions for a HT simulation inside the solid domain. The converged solution on the skin at the interface between fluid and solid domains is displayed in Fig. 9 for those two engine cycles. Even though these two cycles represent extreme scenarios in terms of fluid-solid heat fluxes, these HT simulations show that the impact on the solid temperature is very low. The mean temperature integrated over the cylinder head and valves is $441 \mathrm{~K}$ for the engine cycle with the highest heat fluxes while it is equal to $438 \mathrm{~K}$ for the engine cycle with the lowest heat fluxes. As expected, the highest temperatures are found on the exhaust valves but they vary only from $607 \mathrm{~K}$ for the low flux cycle 


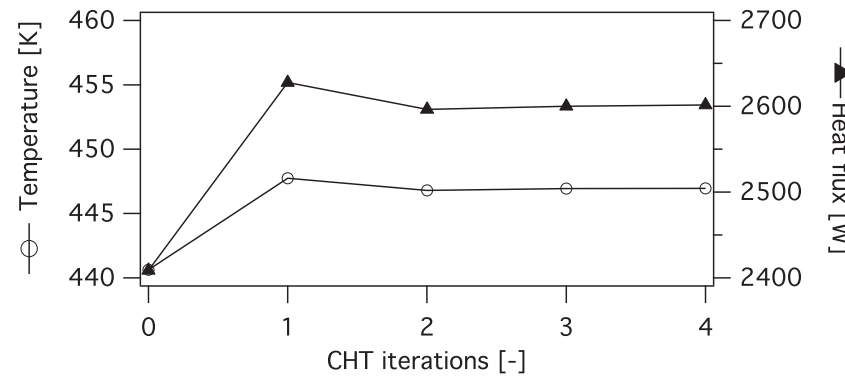

Fig. 10. Convergence of the mean temperature and heat fluxes at the interface between the fluid and solid domains.

to $611 \mathrm{~K}$ for the high flux cycle. In other words, temperature in the solid is mainly driven by heat exchanges with the ambient air and coolant fluid and its sensitivity to variations of the heat flux coming from the fluid domain is low. This shows that the temperature field in the engine walls is almost insensitive to the details of each cycle and can be computed using the cycle averaged heat fluxes. Note that for the two simulations performed, steady state is reached after about $60 \mathrm{~s}$ of physical time meaning that a synchronized coupling between fluid and solid domains is actually out of reach for this kind of applications.

\subsection{CHT convergence and influence on the fluid solution.}

Figure 10 shows the evolution of the mean solid temperature and the mean heat fluxes integrated over the cylinder head and valves using the algorithm of Fig. 1. Convergence is reached very quickly: at the end of the second CHT iteration, the error compared to the fourth CHT iteration on the mean heat flux is $0.2 \%$ and $0.3 \%$ on the mean temperature. Figure 11 shows the evolution of the skin temperature used as boundary condition for the LES. The quick convergence of the CHT simulation observed for global quantities in Fig. 10 is also observed for the local distribution of the wall temperature. The main advantage of using a CHT methodology is to provide the full wall temperature field while the empirical simulation relies on a user-specified mean temperature for each element of the model (cylinder head, valves). For a more quantitative comparison, temperature profiles on cylinder head and valves (see Fig. 11b for profile positions) are plotted in Fig. 12. These profiles prove that it is difficult to obtain good estimations of wall temperature with an empirical guess. Up to $60 \mathrm{~K}$ variations of temperature are observed on the center of the cylinder head (A-line in Fig. 12a). This is even worse for exhaust valves where the skin temperature at the exhaust valve center is $200 \mathrm{~K}$ higher than its surroundings (B-line in Fig. 12b). The exhaust valve shaft only sees burned gases during the whole engine cycle. On the contrary, the valve tip is cooled down by the cylinder head. The resulting temperature profile in the valve can not be guessed using empirical approaches and $\mathrm{CHT}$ is required to provide consistent temperature fields for LES.

\subsection{Impact of CHT on combustion}

In order to investigate the effect of using realistic wall temperatures, a first multi-cycle LES is performed with empirical wall temperatures. Then each individual cycle is re-played with different wall temperatures from CHT simulations. Table 5 summarize the different cases. Figure 13 shows the pressure evolution for 3 engine cycles with highing knock intensity in $A$-case and $B$-case. In both experiments and LES, knocking cycles are characterized by pressure oscillations: pressure records are used to determine the occurrence of knocking and its onset. For a fair comparison between experiments (where 500 cycles are captured) and LES (which only contains 15 cycles) samples

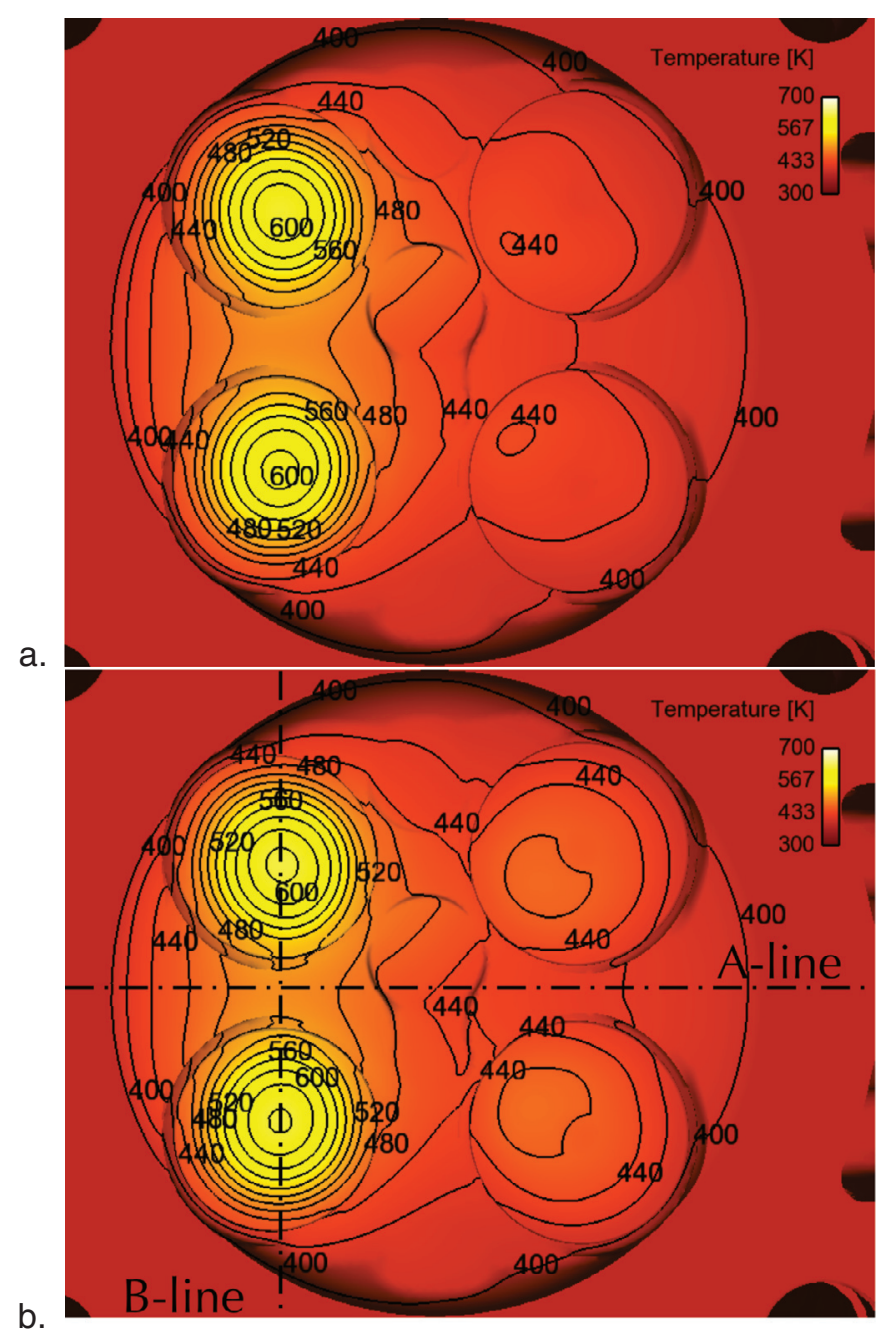

Fig. 11. Convergence of the CHT simulation. (a) Converged solution in the solid after the first CHT iteration and (b) converged solution after the fourth CHT iteration.
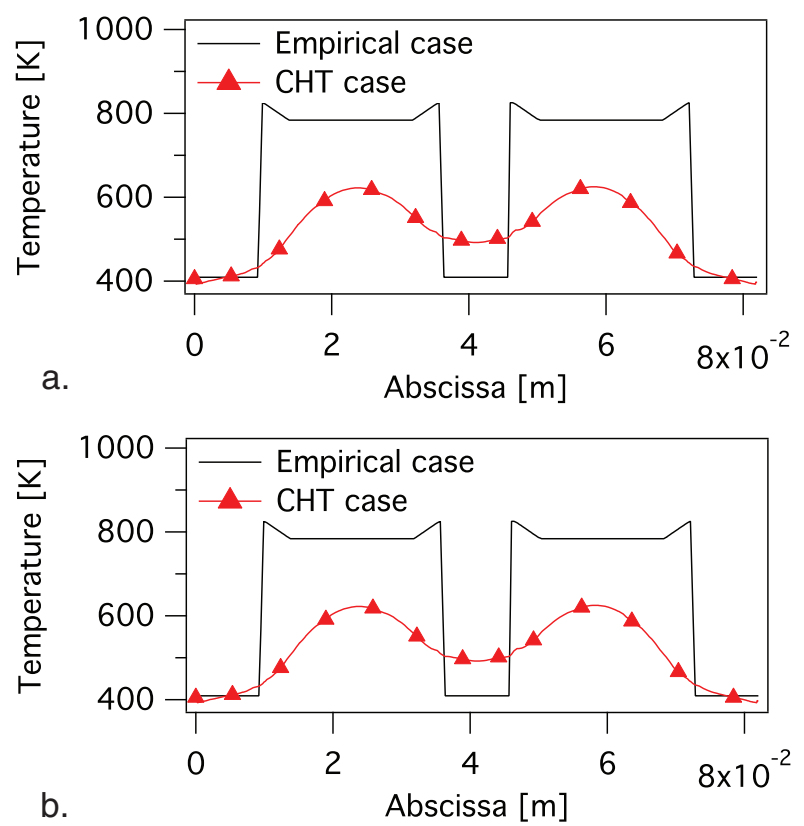

Fig. 12. Temperature profiles on cylinder head and exhaust valves for empirical and CHT. A-line (a) and B-line (b). The empirical profiles are specified by the user as boundary condition while the $C H T$ profiles are a result of the coupled simulation. 


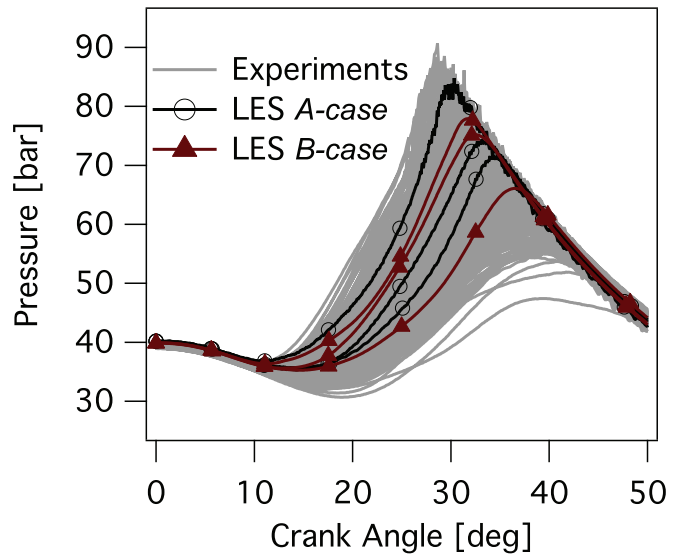

Fig. 13. Temporal evolution of the in-cylinder pressure recorded by a pressure probe for 3 engine cycles with high knocking intensity. (a) Corresponds to A-case and (b) corresponds to $B$-case.

Table 5

Definition of LES cases. Spark timing is given with reference to TDC. $N u_{c}$ is a Nusselt Number that characterizes the contact between valves and cylinder head.

\begin{tabular}{lllll}
\hline Case & Spark timing [CAD] & Wall temperature & $\mathrm{Nu} u_{c}$ & Knocking \\
\hline A-case & +6 & Empirical & - & Yes \\
B-case & +6 & CHT & 0.3 & No \\
C-case & +6 & CHT & 0.6 & Yes \\
D-case & 0 & CHT & 0.6 & Yes \\
E-case & -4 & CHT & 0.6 & Yes \\
\hline
\end{tabular}

Table 6

Comparison of knocking statistics between experiments and LES.

\begin{tabular}{lll}
\hline & Knocking cycles [\%] & Knock onset [CA aTDC] \\
\hline Exp. (500 cycles) & 51.51 & 31.61 \\
Exp. (15 cycles) & {$[13.34-80.0]$} & {$[29.91-35.24]$} \\
LES A-case & 40.00 & 32.56 \\
LES B-case & 0.00 & - \\
LES C-case & 53.00 & 32.90 \\
\hline
\end{tabular}

of 15 experimental cycles are used to compute the same statistics (Table 6). These statistics show that the numerical setup including TFLES and IPRS model for combustion modeling is able to reproduce the knocking behavior in the A-case. For the B-case simulation however, no knocking cycles are observed. The cycles plotted are the same for the two cases. The combustion process differs between the two simulations even during the propagation of the flame but the most remarkable result is that in $B$-case, no oscillations representative of knocking are observed. The difference in the combustion process can be attributed to slight changes due to the different temperature of the walls. These skin temperature differences induce not only gas temperature differences but also flow modifications (Fig. 14): the combination of temperature and flow variations between $A$ and $B$-Cases eventually leads to very different knocking results. Under the same operating conditions, [13] observed that auto-ignition of the end-gas mainly occurred near the hot exhaust valves. In the present results, the absence of knocking in $B$-case is indeed due to the lower exhaust valve temperature compared to A-case. In A-case, the exhaust valve temperature was set to $784 \mathrm{~K}$ while it shows large local variations in the CHT simulation but does not exceed $620 \mathrm{~K}$ (Figs. 11 and 12). Figure 15 shows iso-surfaces of temperature at $780 \mathrm{~K}$ and $800 \mathrm{~K}$ for the same cycle as in Fig. 14, 2 CAD after ignition for the empirical ( $A$ case) and the CHT (B-case) LES. The distribution of hot spots clearly differs between the two simulations and more particularly, the large hot spot observed above the hot exhaust valve in A-case disappears

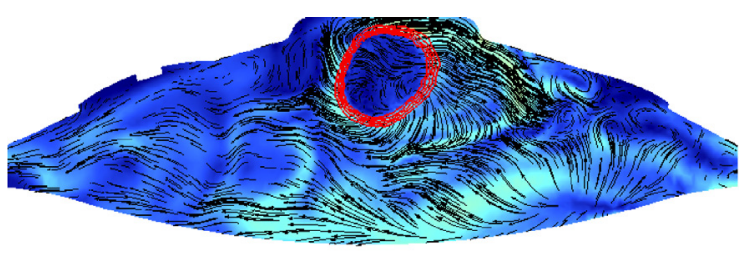

a.
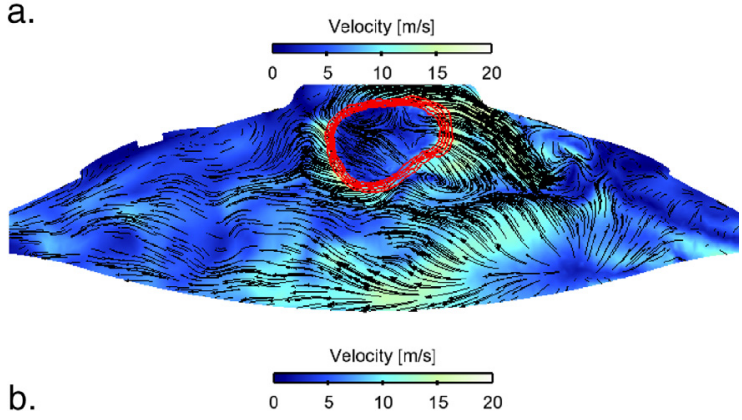

Fig. 14. Aerodynamic field in a $(\vec{x}, \vec{z})$ cut-plane and iso-surfaces of temperature 2 CAD after ignition for $A$-case (a) and $B$-case (b). This cycle corresponds to the cycle with the highest knocking intensity for $A$-case.

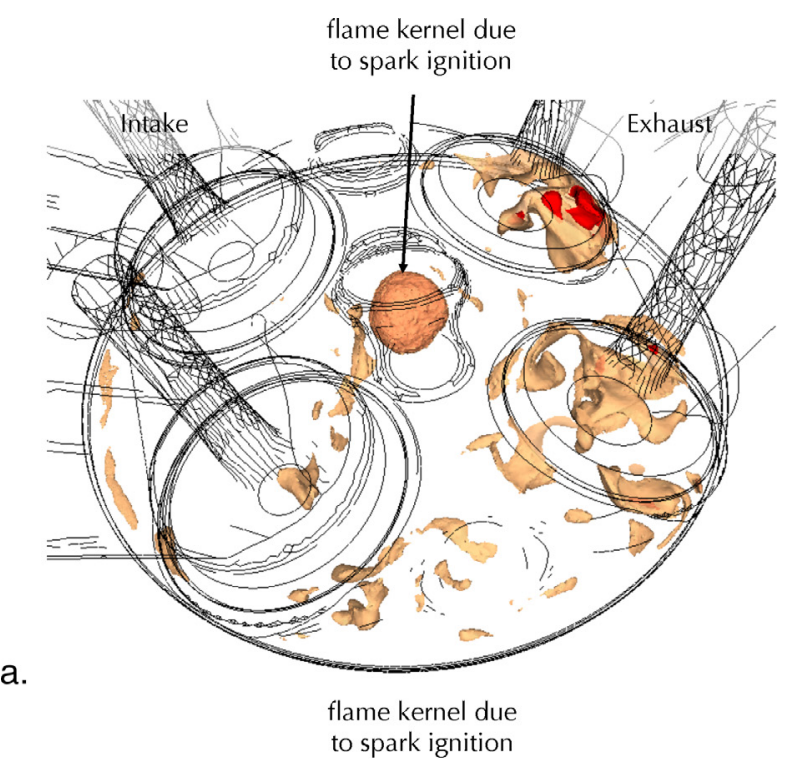

b.

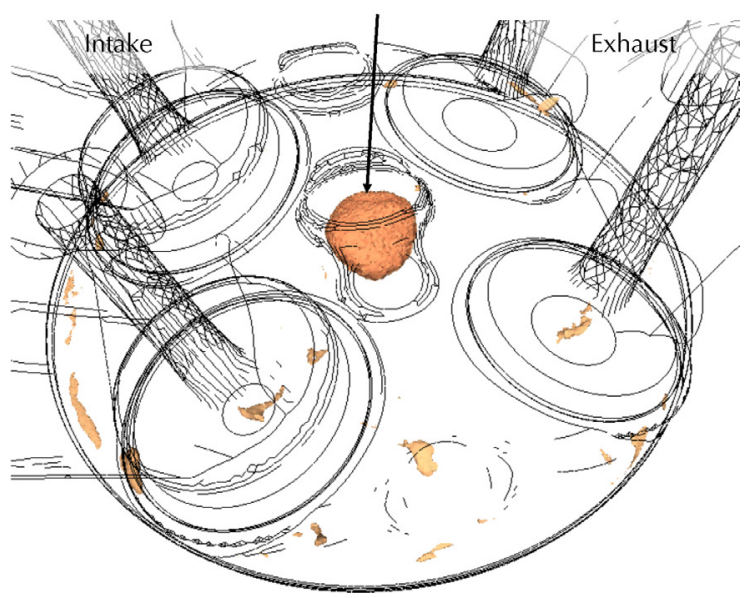

Fig. 15. $780 \mathrm{~K}$ and $800 \mathrm{~K}$ temperature iso-surfaces $2 \mathrm{CAD}$ after spark timing for the cycle with highest knock intensity in A-case (a) and B-case (b). This cycle corresponds to the cycle with the highest knocking intensity. 


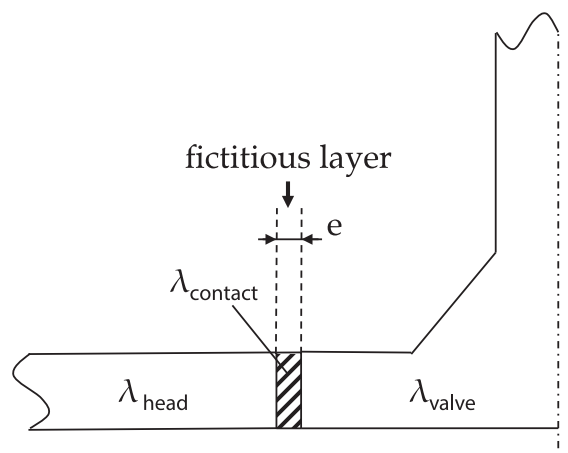

Fig. 16. Illustration of the fictitious layer model to account for teat transfer between cylinder head and valves.

in $B$-case. This zone corresponds to the location where auto-ignition eventually occurs in A-case explaining why B-case does not create knocking. This simulation shows that autoignition is extremely sensitive to local temperature properties: improving the boundary conditions (going from an empirical temperature field to a fully computed temperature field) on the engine walls is sufficient to inhibit knocking. This confirms that wall boundary conditions are crucial to predict knocking. Even if the CHT methodology provides a better description of wall temperatures, it actually degrades knocking predictions because it lead to too low temperature of the exhaust valves. It suggests that the CHT approach used in this section must be improved. The next section shows that the most critical part of this method is the description of the contact between exhaust valves and cylinder head.

\subsection{Improvement of the CHT model.}

This section shows how to improve the CHT approach and capture knocking when it should occur. For the sake of simplicity, the model previously used for the CHT simulation assumed:

- A closed position of the valves during the whole cycle.

- No contact resistance between cylinder head and valves when valves are closed.

These assumptions have a major impact on heat fluxes between cylinder head and exhaust valves. The main problem is that assuming closed position and perfect contact between head and valves during the whole cycle over-predicts the cooling of the hot valves by the water-cooled cylinder head. The heat flux in this region actually follows a cyclic evolution: it is high when the valve is closed and it is zero when the valve is open. The typical exhaust phase duration is 200 CAD which represents $28 \%$ of the whole cycle. Heat diffusion inside the solid does not see the valve motion because of its high frequency but this motion has an impact on the mean fluxes through the cylinder head-valve interface. This section describes a simple improvement technique to account for the reduced valve heat fluxes due to the period when valves are open and to the contact resistance between the two parts. The flux $\Phi$ between cylinder head and valve can be expressed as follows:

$\Phi=\tau_{\text {closed }} \frac{T_{h}-T_{v}}{R_{c}}$

with $\tau_{\text {closed }}$ the ratio between the duration when the valve is closed to the cycle duration $\left(\tau_{\text {closed }}=0.3\right) . T_{h}$ and $T_{v}$ represent the cylinder head and valves temperature and $R_{C}$ is the contact resistance $R_{C}$ between head an valves. Eq. (3) suggests a simple method (called here fictitious layer) to account for the reduced heat flux due to contact resistance and valve opening without having to actually use a geometry where the valves move. A small 'contact' zone of thickness $e\left(e=0.3 \mathrm{~mm}\right.$ here) and conductivity $\lambda_{\text {contact }}$ (Fig. 16) can be placed between valves and cylinder head. The conductivity $\lambda_{\text {contact }}$

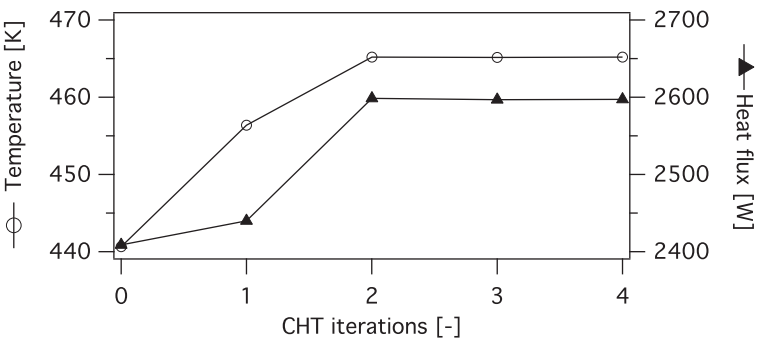

Fig. 17. Convergence of the mean temperature and heat fluxes at the interface between the fluid and solid domains with $N u_{\text {contact }}=0.6$.

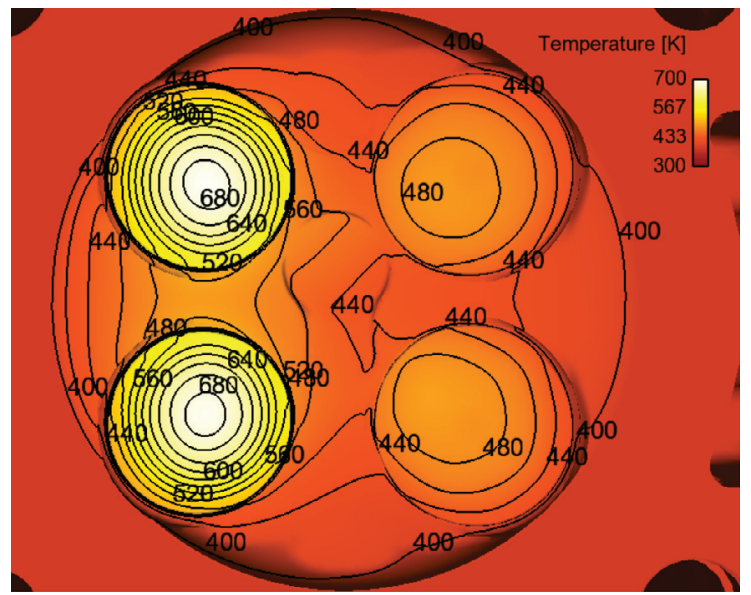

Fig. 18. Temperature field at the fluid/solid interface after the fourth CHT iteration.

can be chosen so that the heat flux through this layer $\Phi_{\text {contact }}=$ $\lambda_{\text {contact }}$. $\left(T_{h}-T v\right) / e$ matches the flux given in Eq. (3). This is obtained for: $\lambda_{\text {contact }}=\tau_{\text {closed }} . e / R_{c}$. It is convenient to scale $\lambda_{\text {contact }}$ by the conductivity of the valves to have:

$\frac{\lambda_{\text {contact }}}{\lambda_{\text {valves }}}=\frac{\tau_{\text {closed }}}{N u_{c}}$

where $N u_{c}$ is a contact Nusselt number. This allows to mimic the effect of valve opening on the valve temperature while still using a fixed geometry. $\mathrm{Nu}_{c}$ is difficult to evaluate and remains an input for the simulation. In the following ( $C$-case, $D$-case and $E$-case) it is set to $N u_{c}=0.6$. For $B$-case where the layer of thickness $e$ was supposed to be made of steel, $N u_{c}$ is equal to $\tau_{\text {closed }}=0.3$ by construction.

The convergence of this modified CHT simulation is displayed Fig. 17. As in the previous case, a steady state in terms of mean temperature and mean heat flux is obtained after the second CHT iteration. Figure 18 shows the spatial distribution of temperature after the fourth CHT iteration. Compared to the B-case simulation (Fig. 11b) higher temperatures are observed. The temperature of the exhaust valve center increases from $605 \mathrm{~K}$ to $690 \mathrm{~K}$. It is interesting to see that, once one tries to compute wall temperatures with precision, details become important: the present results show that assuming that valves remain closed all the time leads to under predicted wall temperatures and, as shown above, to underestimated knocking. Correcting this problem with the model of Fig. 16 and Eq. (4) is sufficient to capture knocking cycles again: for a third multi-cycle simulation called C-case, 53\% of knocking cycles are found with a mean onset at 32.9 CAD which matches experimental results (Fig. 19).

Finally, the same wall temperatures (from C-case) are kept to compute $D$-case and E-case with variable spark timing. Figure 20 shows the evolution of the local pressure for three knocking cycles with high knocking intensity. The global trends from [13] are retrieved. When the spark timing is reduced, higher pressure levels are observed 


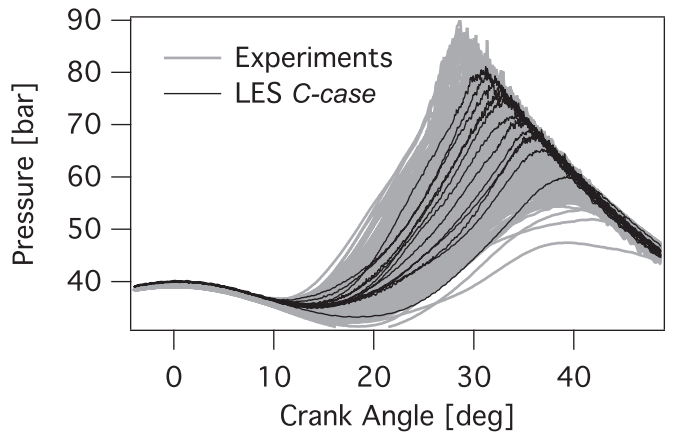

Fig. 19. Temporal evolution of the in-cylinder pressure recorded by a pressure probe in C-case( 15 cycles).

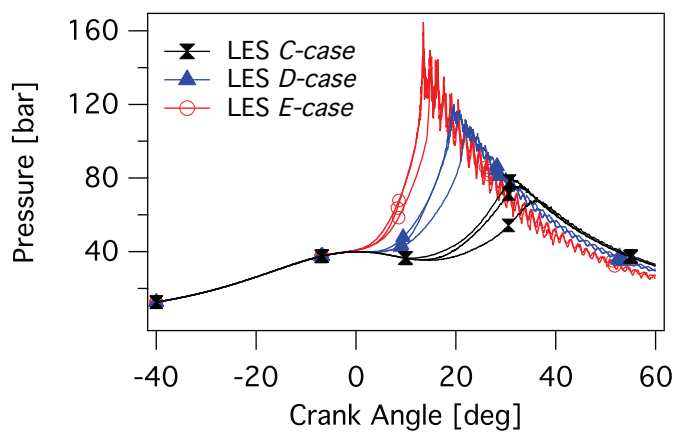

Fig. 20. Temporal evolution of the in-cylinder pressure for 3 cycle with high knocking intensity for $C$-case, $D$-case and $E$-case.

inside the cylinder. Auto-ignition occurs sooner in the cycle and knocking intensity is increased.

These simulations show that wall temperatures have a direct impact on the flow motion and on the combustion process. Especially when dealing with abnormal combustions, the auto-ignition delay can vary dramatically as a function of the local temperature conditions and an accurate prediction of the thermal boundary conditions is necessary. Even though the proposed model including a CHT simulation still uses some assumptions such as the definition of a contact Nusselt number, it replaces a complete field of uncertainties (the wall temperature field) by only one input (the contact Nusselt number). This permits to obtain local distributions of temperature that should be close to the physical behavior and compatible with LES precision.

\section{Conclusions}

In order to increase the precision of LES of knocking in piston engines, this paper focuses on a strategy that permits to access to a realistic wall temperature field in the combustion chamber. The proposed methodology relies on a full Conjugate Heat Transfer (CHT) simulation between cylinder head, valves and the combustion chamber which provides all wall temperatures. These temperatures control the engine behavior, especially in terms of knocking showing the importance of this input for precise LES. The second part of this paper addresses the issue of heat transfer between cylinder head and moving valves. A simple methodology is proposed to account for this moving geometry and contact resistance in this region. LES performed in this paper show a strong impact of heat transfer and skin wall temperatures on the knocking behavior of the engine. The use of a CHT simulation instead of a priori defined, constant wall temperatures changes the distribution of hot spots that are likely to auto-ignite. This clear improvement of the LES strategy allows to provide more physical, meaningful data but results show that it also bring a new complexity: to model the valves temperatures (which control the knock onset), the heat resistance between valve and head must be correctly modeled and introduced in the CHT model, something which is not fully available today.

\section{Acknowledgments}

This work was granted access to the HPC resources of CCRT under allocations x20142b5031 made by GENCI (Grand Equipement National de Calcul Intensif) and PRACE (Partnership for Advance Computing in Europe) project N2013091887 SolitonCycLES. The authors acknowledge the financial support by the French ANR under grant ANR-10-VPTT-0002 ICAMDAC.

\section{References}

[1] G.T. Kalghatgi, SAE Trans. J. Fuels Lubr. 105 (1995).

[2] K.M. Chun, J.B. Heywood, SAE Paper (1989).

[3] T. Litzinger, Prog. Energy Combust. Sci. 16 (1990) 155-167.

[4] G.A. Ball, Proc. Combust. Inst. 5 (1955) 366-372.

[5] N. Kawahara, E. Tomita, Y. Sakata, Proc. Combust. Inst. 31 (2007) 2999-3006

[6] M. Kanti, N. Kawahara, E. Tomita, Proc. World Hydrogen Energy Combust. 78 (2010) 141-148.

[7] K. Chun, J. Heywood, J. Keck, Proc. Combust. Inst. 22 (1989) 455-463, doi:10.1016/S0082-0784(89)80052-9.

[8] Y.B. Zeldovich, Combust. Flame 39 (1980) 211-214.

[9] D. Bradley, G.T. Kalghatgi, Combust. Flame 156 (2009) 2307-2318.

[10] P. Clavin, L. He, J. Fluid Mech. 306 (1996) 353-378, doi:10.1017 S0022112096001334.

[11] K. Fieweger, R. Blumenthal, G. Adomeit, Combust. Flame 109 (1997) 599-619.

[12] N. Peters, B. Kerschgens, G. Paczko, SAE Paper (2012).

[13] A. Robert, S. Richard, O. Colin, L. Martinez, L.D. Francqueville, Proc. Combust. Inst. 35 (2015) 2941-2948, doi:10.1016/j.proci.2014.05.154.

[14] Y. Li, S. Kong, Int. J. Heat Mass Transf. 54 (2011) 2467-2478.

[15] D. Linse, A. Kleemann, C. Hasse, Combust. Flame 161 (2014) 997-1014

[16] B. Enaux, V. Granet, O. Vermorel, C. Lacour, L. Thobois, V. Dugué, T. Poinsot, Flow Turbul. Combust. 86 (2011) 153-177.

[17] V. Granet, O. Vermorel, C. Lacour, B. Enaux, V. Dugué, T. Poinsot, Combust. Flame 159 (2012) 1562-1575.

[18] D. Goryntsev, A. Sadiki, M. Klein, J. Janicka, Proc. Combust. Inst. 32 (2009) 27592766.

[19] A.H. Lefebvre, Gas Turbines Combustion, Taylor \& Francis, 1999

[20] S. Richard, O. Colin, O. Vermorel, A. Benkenida, C. Angelberger, D. Veynante, Proc. Combust. Inst. 31 (2007) 3059-3066.

[21] B. Enaux, V. Granet, O. Vermorel, C. Lacour, C. Pera, C. Angelberger, T. Poinsot, Proc Combust. Inst. 33 (2011) 3115-3122.

22] V. Granet, O. Vermorel, T. Leonard, L. Gicquel, T. Poinsot, AIAA J. 48 (2010) 2348 2364

[23] C. Pera, C. Angelberger, SAE Paper (2011)

[24] T. Schønfeld, T. Poinsot, in: Annual Research Briefs, Center for Turbulence Research, NASA Ames/Stanford Univ., 1999, pp. 73-84.

[25] L.Y.M. Gicquel, G. Staffelbach, T. Poinsot, Prog. Energy Combust. Sci. 38 (2012) $782-817$.

[26] A. Misdariis, A. Robert, O. Vermorel, S. Richard, T. Poinsot, Oil Gas Sci. Technol. Rev. IFP Energ. Nouv. 69 (2014) 83-105, doi:10.2516/ogst/2013121.

[27] P.D. Lax, B. Wendroff, Com. Pure App. Math. 17 (1964) 381-398.

[28] O. Colin, M. Rudgyard, J. Comput. Phys. 162 (2000) 338-371.

[29] J. Smagorinsky, Mon. Weather Rev. 91 (1963) 99-164.

[30] T. Poinsot, S. Lele, J. Comput. Phys. 101 (1992) 104-129, doi:10.1016/00219991(92)90046-2.

[31] P. Quillatre, O. Vermorel, T. Poinsot, P. Ricoux, Ind. Eng. Chem. Res. 52 (2013) 11414-11423.

[32] P. Schmitt, T. Poinsot, B. Schuermans, K.P. Geigle, J. Fluid Mech. 570 (2007) 17-46

[33] G. Kuenne, A. Ketelheun, J. Janicka, Combust. Flame 158 (2011) 1750-1767.

[34] L. Gicquel, G. Staffelbach, T. Poinsot, Prog. Energy Combust. Sci. 38 (2012) 782817.

[35] A. Misdariis, O. Vermorel, T. Poinsot, Proc. Combust. Inst. 35 (2015) 3001-3008.

[36] S. Jerzembeck, N. Peters, P. Pepiot-Desjardins, H. Pitsch, Combust. Flame 156 (2009) 292-301.

[37] G. Lacaze, E. Richardson, T.J. Poinsot, Combust. Flame 156 (2009) 1993-2009.

[38] C.W. Hirt, A. Amsden, J.L. Cook, J. Comput. Phys. 131 (1974) 371-385.

[39] O. Cabrit, F. Nicoud, Phys. Fluids 21 (2009) 055108, doi:10.1063/1.3123528.

[40] O. Vermorel, S. Richard, O. Colin, C. Angelberger, A. Benkenida, D. Veynante, Combust. Flame 156 (2009) 1525-1541.

[41] F. Duchaine, N. Maheu, V. Moureau, G. Balarac, S. Morea, Journal of Turbomachinery 136 (2013) 051015

[42] J. Donea, A. Huerta, Finite Element Methods for Flow Problems, John Wiley \& Sons 2003.

[43] V. Frayssé, L. Giraud, S. Gratton, J. Langou, ACM Trans. Math. Softw. 31 (2005) 228-238, doi:10.1145/1067967.1067970.

[44] A. Robert, Simulation Aux Grandes Echelles Des Combustions Anormales Dans Les Moteurs Downsizés à Allumage Commandé, INP Toulouse, 2014 (Ph.D. thesis)

[45] Y. Aabdel-Fattah, The Mechanics of Valves Cooling in Internal-Combustion Engines: Investigation into the Effect of Valve-Seat Inserts on the Heat Flow from Valves towards the Cooling Jacket, University of Bradford, 2009 (Ph.D. thesis). 